\title{
The Role of Institutional Quality in a Currency Crisis Model
}

\author{
$Y i W u$
}





\title{
IMF Working Paper
}

Policy Development and Review

\section{The Role of Institutional Quality in a Currency Crisis Model}

\author{
Prepared by Yi Wu
}

Authorized for distribution by Thomas Dorsey

January 2008

\begin{abstract}
This Working Paper should not be reported as representing the views of the IMF.

The views expressed in this Working Paper are those of the author(s) and do not necessarily represent those of the IMF or IMF policy. Working Papers describe research in progress by the author(s) and are published to elicit comments and to further debate.

This paper is a theoretical study of the impact of institutional quality on currency crises from a public finance point of view. Recent empirical studies leave little doubt that weak institutions, including high levels of corruption, hinder economic performance. After the East Asian crisis, many observers have pointed to widespread corruption and crony capitalism as an underlying cause. Despite the popularity of the claim, there are only limited empirical and especially theoretical studies on the link between institutional quality and currency crises. This paper intends to fill in this void. We model institutional weakness as an inefficiency of the tax collection system. The model derived here shows that institutional weakness generally increases the likelihood of the existence of a self-fulfilling crisis equilibrium, and leads to larger currency devaluation when crises happen. However, this relationship could reverse when institutional weakness is very severe.
\end{abstract}

JEL Classification Numbers:F39

Keywords: Institution quality; currency crisis

Author’s E-Mail Address:ywu@imf.org

* I am grateful to Shang-Jin Wei for suggesting this research and guidance. I also thank Robert E. Cumby and Holger C. Wolf for very helpful comments. All remaining errors are my own. The views expressed herein are those of the author and should not be attributed to the IMF, its Executive Board, or its management. 


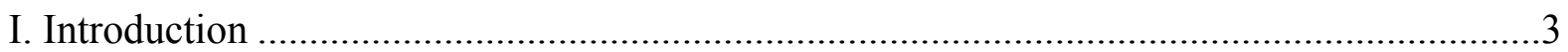

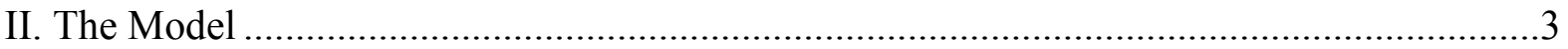

III. Institutional quality and self-fulfilling currency crises ........................................... 12

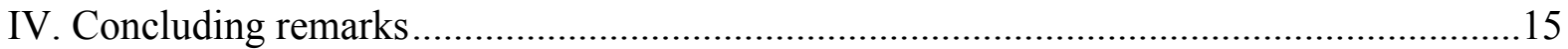

Figures

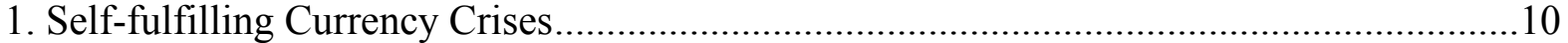

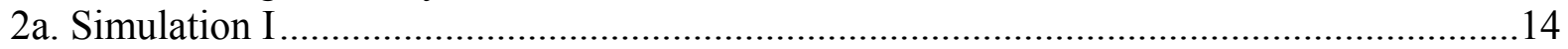

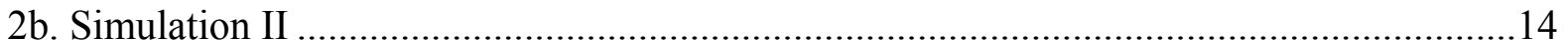








\section{INTRODUCTION}

This paper is a theoretical study of the impact of weak institutions on currency crises from a public finance point of view. Recent empirical studies leave little doubt that weak institutions, including high levels of corruption, hinder economic performance (see, for example, Mauro, 1995; Wei, 2000a; Acemoglu et al., 2001). Countries with weak institutions are found to invest less, attract less foreign direct investment, and grow more slowly. After the East Asian crisis, many observers have pointed to widespread corruption and crony capitalism as an underlying cause. Despite the popularity of the claim, there are only limited empirical and theoretical studies on the link between institutional quality and currency crises. On the empirical side, Johnson et al. (2000) find that the emerging market countries with weaker institutions also experienced larger depreciation during the Asian crisis. Wei (2000b) shows corruption affects a country's composition of capital inflows in a way that makes it more likely to experience a currency crisis. Radelet and Sachs (1998), however, find no evidence that corruption increases the probability of currency crises for a sample of twenty two emerging market countries over the period of 1994 to 1997.

On the theoretical side, Johnson et al. (2000) argue that weak corporate governance makes it easier for managers to steal assets and take them out of the country in bad times, thus exacerbating the situation, even leading to financial/currency crises. This could explain why weak institutions, which change little over time, can cause financial/currency crises, which are occasional events.

In this paper, we follow Huang and Wei (2006) to model weak institutions as an inefficiency of the tax collection system, and analyze the link between weak institutions and currency crises from a public finance point of view using an extended Obstfeld (1996) type model. The model derived here shows that weak institutions generally increase the likelihood of the existence of a self-fulfilling crisis equilibrium and lead to larger currency devaluation when crises happen. However, this relationship could reverse when institutional weakness is very severe.

The paper is organized as follows. Section 2 describes the framework of the model. Section 3 analyzes the link between weak institutions and currency crises, and section 4 provides some concluding remarks.

\section{THE MODEL}

The first generation model of currency crises (Krugman, 1979) viewed currency crises as the inevitable outcome of growing fiscal imbalances coupled with fixed exchange rates. Obstfeld (1994, 1996, 1997) developed the second generation model with multiple equilibria where

crises could be driven by self-fulfilling expectations. In these models, the government finds it optimal to abandon an exchange rate peg when the output cost of defending it becomes too large, with the cost itself a function of the expectations of private agents. The basic 
framework of our model is drawn from Obstfeld (1996), which itself is based on Barro and Gordon (1983).

The government minimizes the following loss function

$$
L=\left(y-y^{*}\right)^{2}+\beta \varepsilon^{2}+\gamma(g-\bar{g})^{2}+C(\varepsilon),
$$

where $y$ is the $\log$ of real output, and $y^{*}$ is the log of government's real output target. $\varepsilon=e-e_{-1}$ is the change in the (log of) exchange rate, where the exchange rate is defined as the price of foreign currency in terms of domestic currency. Following Obstfeld (1994, 1996, 1997), we assume PPP holds and normalize the foreign price level at unity. The exchange rate is thus identified with the domestic price level.

The ratio of public expenditures to output is defined as $g$. The introduction of public goods provision is where eq. (1) differs from the original Obstfeld setup. The time inconsistency problem of the optimal monetary policy (Barro and Gordon, 1983) is based on the hypothesis that the central bank has an incentive to generate unexpected shocks so as to reduce unemployment below the level that would be otherwise determined by the market. Two reasons have been suggested in the literature to justify this hypothesis: 1) labor market imperfections which force the equilibrium real wage above the level compatible with full employment, and 2) the existence of tax distortions that reduce the level of activity below the level compatible with full employment. Alesina and Tabellini (1987) pointed out that the second reason was more general because even if market imperfections forced real wages above the socially optimum level, firms could be subsidized to reach the desired level of employment and these subsidies could be financed with a nondistortionary tax, if it existed. They further argue that since the distortionary tax collection is driven by the government's need to finance public expenditures, it would be desirable to model the provision of public goods explicitly. As in their model, we assume the policy makers wish to minimize the deviations of public expenditures from a positive target, $\bar{g}$.

Finally, $C(\varepsilon)$ represents a fixed cost the government has to incur to abandon the exchange rate peg. This could be, for example, a loss of credibility. Without the fixed cost, as will be shown later, floating will always be a dominating strategy.

The supply function is derived in a way similar to that of Alesina and Tabellini (1987), where competitive firms uses only labor as an input and are subject to a revenue tax. The production function of a representative firm is

$$
Y=A N^{\prime \prime}, \quad 0<\gamma<1,
$$

where $Y$ is the real output, $A$ denotes an i.i.d. random shock to output, and $N$ represents the labor input. The firm solves the following optimization problem

$\operatorname{Max} P(1-\tau) Y-W N$ 
The firm is a price taker in the output and in the labor market with $P$ and $W$ denotes price and wage levels respectively. $\tau$ is the tax rate on firm's revenue. Solving the first order condition we obtain:

$$
y=\frac{\gamma}{1-\gamma}(\operatorname{Ln} \gamma+p-\omega-\tau)+\frac{a}{1-\gamma}
$$

where the lower case letters denote the log of the upper case letters. To get eq. (2) we have also applied the approximation $\ln (1-\tau)=-\tau$.

Nominal wages are set a period in advance in the labor market where a trade union (TU) minimizes a loss function as the deviation of the real wage from a target $v$,

$$
L^{T U}=(w-p-v)^{2}
$$

The first order condition is simply

$$
w=p^{e}+v
$$

where $p^{e}$ is the expected price level. Plugging it back into eq. (2) we can rewrite the supply equation as

$$
y=\frac{\gamma}{1-\gamma}(\operatorname{Ln} \gamma-v)+\frac{\gamma}{1-\gamma}\left(\varepsilon-\varepsilon^{e}-\tau\right)+\frac{a}{1-\gamma} .
$$

This is the expectations-augmented Phillips curve where $\varepsilon^{e}$ is domestic price-setters' expectation of $\varepsilon$ based on lagged information. With $v>0$, the real wage targeted by the trade union makes the output lower than the level desired by the policy makers. As a simplification and without loss of generality, we set $v=0$ which would correspond to a competitive labor market. Thus $\frac{\gamma \ln \gamma}{1-\gamma}$ would correspond to the output level desired by the policy makers, $y^{*}$. The output distortion comes only from the tax $\tau$, which Alesina and Tabellini (1987) have argued was the more general cause. Further define $\alpha \equiv \frac{\gamma}{1-\gamma}$ and $u \equiv \frac{-\alpha}{1-\gamma}$, eq. (3) can be rewritten as

$$
y=y^{*}+\alpha\left(\varepsilon-\varepsilon^{e}-\tau\right)-u,
$$

In the derivation below we set $y^{*}=0$ to simplify the notation. Eq. (1) and eq.(4) then become

$$
L=y^{2}+\beta \varepsilon^{2}+\gamma(g-\bar{g})^{2}+C(\varepsilon)
$$

and

$$
y=\alpha\left(\varepsilon-\varepsilon^{e}-\tau\right)-u,
$$


where let us assume $u$ is an i.i.d. mean-zero shock, which is realized after the private agents form their expectations but before the government authorities decide on their policies.

The next question is how to introduce institutional quality into this framework. Huang and Wei (2006), in a study of the impact of institutional quality on optimal monetary policy for developing countries, argue that the government's fiscal capacity is adversely affected by weak institutions (e.g., corruption). If the private sector pays a tax in the amount of $\tau$, only a portion of it goes to the government. Following Huang and Wei (2006), we model weak institutions as a leakage of tax revenue. Furthermore, as in Alesina and Tabellini (1987), we ignore the intertemporal dimension of the government budget constraint by assuming that public expenditures cannot be financed by issuing public debt. The assumption that there is no public debt considerably simplifies the analysis. As a result, however, we are not able to address the issue of intertemporal allocation of tax distortions. After some simplifications and approximations, ${ }^{1}$ the government's budget constraint can be written as

$$
g=(1-\phi) \tau+\varepsilon
$$

where $0<\phi<1$, denotes the degree of institutional weakness, with higher values of $\phi$ representing lower quality of institutions. Eq. (7) shows there are two sources of revenue to finance the public goods provision: corporate tax and seigniorage (devaluation). The measurement of institutional weakness, $\phi$, can therefore be thought of as a fiscal capacity index. Weakness in institutions thus increases the shadow price of raising revenue from the formal tax channels relative to the inflation tax/devaluation.

The government chooses $\tau$ and $\varepsilon$ after the output shock, $u$, is observed. ${ }^{2}$ Since any change in the exchange rate will incur a fixed cost, the government will choose to realign only if the overall social loss of doing so is smaller than the cost of staying fixed.

Under a floating regime, the government would choose

$$
\varepsilon^{\text {Float }}=\frac{\alpha\left(u+\alpha \varepsilon^{e}\right)+\tau^{\text {Float }}\left[\alpha^{2}-\gamma(1-\phi)\right]+\gamma \bar{g}}{\alpha^{2}+\beta+\gamma},
$$

and

$$
\tau^{\text {Float }}=\frac{-\alpha\left(u+\alpha \varepsilon^{e}\right)+\varepsilon^{\text {Float }}\left[\alpha^{2}-\gamma(1-\phi)\right]+\gamma \bar{g}(1-\phi)}{\alpha^{2}+\gamma(1-\phi)^{2}}
$$

\footnotetext{
${ }^{1}$ See footnote 7 of Alesina and Tabellini (1987).

${ }^{2}$ One can think of the current setup as the monetary authority and the fiscal authority chose $\varepsilon$ and $\tau$ respectively but sharing the same objective function. The basic results derived below should pass through if the parameters of the welfare function differ across the two authorities.
} 
Combining eqs. (7) and (8) yields government's policy responses under a floating regime

$$
\varepsilon^{\text {Float }}=\frac{\alpha \gamma(1-\phi)(2-\phi)\left(u+\alpha \varepsilon^{e}\right)+\alpha^{2} \gamma \bar{g}(2-\phi)}{\beta\left[\alpha^{2}+\gamma(1-\phi)^{2}\right]+\alpha^{2} \gamma(2-\phi)^{2}},
$$

and

$$
\tau^{\text {Float }}=\frac{-\alpha\left(u+\alpha \varepsilon^{e}\right)[\beta+\gamma(2-\phi)]+\gamma \bar{g}\left[\alpha^{2}(2-\phi)+(1-\phi) \beta\right]}{\beta\left[\alpha^{2}+\gamma(1-\phi)^{2}\right]+\alpha^{2} \gamma(2-\phi)^{2}},
$$

The government will chose an expenditure level of

$$
g^{\text {Float }}=\frac{-\alpha \beta(1-\phi)\left(u+\alpha \varepsilon^{e}\right)+\gamma \bar{g}\left[\alpha^{2}(2-\phi)^{2}+\beta(1-\phi)^{2}\right]}{\alpha^{2} \beta+\beta \gamma(1-\phi)^{2}+\alpha^{2} \gamma(2-\phi)^{2}},
$$

and output will be

$$
y^{\text {Float }}=\bar{y}+\frac{-\beta(1-\phi)^{2}\left(u+\alpha \varepsilon^{e}\right)-\alpha \beta \gamma \bar{g}(1-\phi)}{\beta\left[\alpha^{2}+\gamma(1-\phi)^{2}\right]+\alpha^{2} \gamma(2-\phi)^{2}} .
$$

Finally, the social loss is

$$
L^{\text {Float }}=\frac{\beta \gamma\left[(1-\phi)\left(u+\alpha \varepsilon^{e}\right)+\alpha \bar{g}\right]^{2}}{\beta\left[\alpha^{2}+\gamma(1-\phi)^{2}\right]+\alpha^{2} \gamma(2-\phi)^{2}}+C(\varepsilon) \text {. }
$$

This is the social loss that a government has to incur if it abandons an exchange peg to float. Eventually, we want to compare this loss to the social loss under commitment in order to find the conditions under which the government will decide to float. Before going into that, we first study how institutional quality affects the size of expected depreciation under a floating regime. Taking expectation of the both sides of eq. (10) and imposing $E \varepsilon^{\text {Float }}=\varepsilon^{e}$ under rational expectations, we can derive the expected depreciation under a floating regime, which in equilibrium equals private agents' expectation

$$
E \varepsilon^{\text {Float }}=\varepsilon^{e}=\frac{\alpha^{2} \gamma \bar{g}(2-\phi)}{\beta\left[\alpha^{2}+\gamma(1-\phi)^{2}\right]+\alpha^{2} \gamma(2-\phi)}
$$

The actual realized change in exchange rate is simply

$$
\varepsilon^{\text {Float }}=\frac{\alpha \gamma(1-\phi)(2-\phi) u+\alpha^{2} \gamma \bar{g}(2-\phi)}{\beta\left[\alpha^{2}+\gamma(1-\phi)^{2}\right]+\alpha^{2} \gamma(2-\phi)}
$$


The expected depreciation is larger if the desired public goods provision $\bar{g}$ is high, the aversion to exchange rate change $\beta$ is low, the weight on public goods provision $\gamma$ is high, and the slope of the supply curve $\alpha$ is small.

Differentiating $E \varepsilon^{\text {Float }}$ w.r.t. $\phi$ we obtain

$$
\frac{d E \varepsilon^{\text {Float }}}{d \phi}=\frac{\alpha^{2} \beta \gamma \bar{g}\left[\gamma(1-\phi)(3-\phi)-\alpha^{2}\right]}{\left[\alpha^{2} \beta+\beta \gamma(1-\phi)^{2}+\alpha^{2} \gamma(2-\phi)\right]^{2}} .
$$

Its sign will be positive if

$$
\gamma(1-\phi)(3-\phi)-\alpha^{2}>0
$$

When eq. (15) holds, lower institutional quality will lead to larger expected depreciation. This is more likely to be the case with larger weight on public goods provision, $\gamma$. This is because with larger $\gamma$, the government has stronger desire to meet the public goods provision needs via higher inflation/depreciation when leakage on tax revenue becomes larger with weaker institutions. A smaller slope of the supply curve $\alpha$ will also make the condition in eq. (15) more likely to hold. This is because as eq. (6) shows, a larger $\alpha$ will cause a larger deviation of output from its target (normalized to be zero). Thus the government would more likely to pursue a larger depreciation with weaker institutions and smaller $\alpha$ since the social cost of deviating from the output target would be smaller.

Finally, the weaker institutions are, the smaller $(1-\phi)(3-\phi)$ will be, and the less likely that eq. (15) will hold. For example, for $\alpha=\gamma=1$ (see below for more discussions on choosing parameter values), eq. (15) holds only when $\phi<0.59$, that is, when the revenue leakage due to weak institutions is less than $59 \%$. The intuition is as follows: weaker institutions generally cause the government to raise the size of depreciation to cover the revenue leakage. When problems with institutions are very severe, however, the depreciation needed could be so large that the gain in welfare from meeting the public goods provision is more than offset by the increase in social loss due to higher inflation/depreciation. Consequently, the optimal depreciation is smaller with weaker institutions. This clearly will be the case when $\varphi$ approaches one regardless of the value of $\alpha$ and $\gamma$. That is, when there is a complete leakage of tax revenue. With zero revenue leakage, the condition in eq. (15) reduces to $3 \gamma>\alpha^{2}$.

Under a fixed exchange rate regime, the only policy instrument available is then the tax rate and the optimal rate is given by

$$
\tau^{F i x}=\frac{-\alpha\left(u+\alpha \varepsilon^{e}\right)+\gamma(1-\phi) \bar{g}}{\alpha^{2}+\gamma(1-\phi)^{2}}
$$


The output level is

$$
y^{F i x}=\bar{y}+\frac{\gamma(1-\phi)^{2}\left(u+\alpha \varepsilon^{e}\right)-\alpha \gamma(1-\phi) \bar{g}}{\alpha^{2}+\gamma(1-\phi)^{2}},
$$

and the welfare loss is

$$
L^{F i x}=\frac{\gamma\left[(1-\phi)\left(u+\alpha \varepsilon^{e}\right)+\alpha \bar{g}\right]^{2}}{\alpha^{2}+\gamma(1-\phi)^{2}},
$$

It is straightforward to see that without the fixed cost of realignment, $C(\varepsilon)$, for a given $\varepsilon^{e}$, the social loss under exchange rate realignment will be always smaller than the loss under commitment. Denote $\bar{c}$ as the fixed cost associated with devaluation and $c$ the fixed cost associated with revaluation. ${ }^{3}$ The government will choose to devalue if the output shock $u$ is so high that $L^{F i x}>L^{\text {Float }}+\bar{c}$ or revalue when $u$ is so low that $L^{F i x}>L^{\text {Float }}+c$. Denote the cutoff value of $u$ for devaluation and revaluation as $\bar{u}$ and $u$ respectively, then

$$
\bar{u}=\frac{\sqrt{\bar{c}} \sqrt{\beta\left[\alpha^{2}+\gamma(1-\phi)^{2}\right]^{2}+\alpha^{2} \gamma\left[\alpha^{2}+\gamma(1-\phi)^{2}\right](2-\phi)^{2}}}{\alpha \gamma(1-\phi)(2-\phi)}-\alpha \varepsilon^{e}-\frac{\alpha \bar{g}}{1-\phi},
$$

and

$$
\underline{u}=\frac{\sqrt{c} \sqrt{\beta\left[\alpha^{2}+\gamma(1-\phi)^{2}\right]^{2}+\alpha^{2} \gamma\left[\alpha^{2}+\gamma(1-\phi)^{2}\right](2-\phi)^{2}}}{\alpha \gamma(1-\phi)(2-\phi)}-\alpha \varepsilon^{e}-\frac{\alpha \bar{g}}{1-\phi},
$$

The government will choose to devalue if $u>\bar{u}$ and revalue if $u<u$. Obviously the higher the expected devaluation rate $\varepsilon^{e}$ is, the lower $\bar{u}$ will be, and the more likely for the condition $u>\bar{u}$ to hold and thus the devaluation to happen. In addition, $\bar{u}$ will also be low if the devaluation $\operatorname{cost} \bar{c}$ is low, the desired public goods provision $\bar{g}$ is high, the devaluation aversion $\beta$ is low, and the weight on public goods provision $\gamma$ is high.

\footnotetext{
${ }^{3}$ These costs are now treated as exogenous. They could be modeled endogenous, e.g., as functions of institutional quality.
} 
Following Obstfeld (1996), let $u$ be uniformly distributed on $[-\mu, \mu]$. The market participants would expect a devaluation if $\mathrm{u}>\bar{u}$, a revaluation if $\mathrm{u}<u$, and no alignment otherwise. The rational expectation of next period's $\varepsilon$, given price setters' expectation $\varepsilon^{e}$, is

$$
E \varepsilon=E(\varepsilon \mid u<\underline{u}) \operatorname{Pr}(u<\underline{u})+O \operatorname{Pr}(\underline{u} \leq u \leq \bar{u})+\mathrm{E}(\varepsilon \mid u>\bar{u}) \operatorname{Pr}(u>\bar{u})
$$

Under the assumed uniform probability distribution for $u$,

$$
\operatorname{Pr}(u<u)=\frac{\mu+u}{2 \mu}, \text { and } \operatorname{Pr}(u>\bar{u})=\frac{\mu-\bar{u}}{2 \mu} .
$$

Given the realignment reaction function (13') and conditioning on the range of $u$ for each scenario

$$
E \varepsilon=\frac{\alpha \gamma(1-\phi)(2-\phi)}{\beta\left[\alpha^{2}+\gamma(1-\phi)^{2}\right]+\alpha^{2} \gamma(2-\phi)^{2}}\left[\alpha \varepsilon^{e}\left(1-\frac{\bar{u}-u}{2 \mu}\right)-\frac{\bar{u}^{2}-u^{2}}{4 \mu}\right]+\frac{\alpha^{2} \gamma(2-\phi) g\left(-\bar{u}\left(1-\frac{\bar{u}-u}{2 \mu}\right.\right.}{\beta\left[\alpha^{2}+\gamma(1-\phi)^{2}\right]+\alpha^{2} \gamma(2-\phi)^{2}}
$$

Note both $\bar{u}$ and $u$ are functions of $\varepsilon^{e}$. On the other hand, in equilibrium $E \varepsilon=\varepsilon^{e}$ and eq. (19) shows that $\varepsilon^{e}$ itself depends on market perceptions of the realignment trigger points, $\bar{u}$ and $u$. It is this element of circularity that makes a fully self-fulfilling crisis à la Obstfeld (1996, 1997) possible. To find the fixed points of eq. (19), figure 1 plots $E \varepsilon$ against $\varepsilon^{e}$ together with a 45 degree line.

\section{Figure 1. Self-fulfilling Currency Crises}

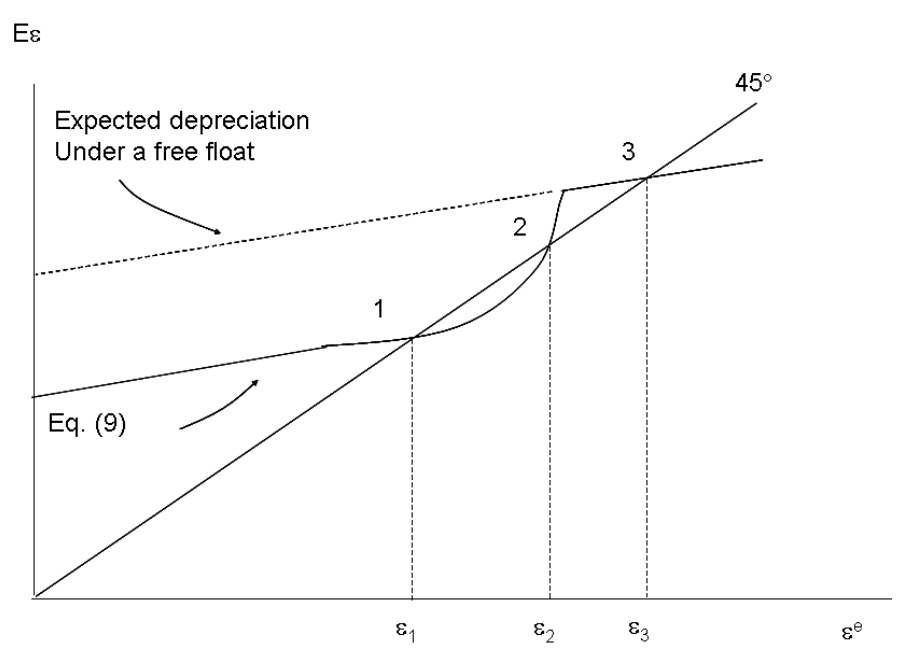


In order to derive the slope of the curve in figure 1, note under the interest rate parity condition, the minimum possible level of $\varepsilon^{e}$ is the value of $\varepsilon^{e}$ that corresponds to the zero domestic interest rate. Thus if $i^{*}$ is the foreign interest rate, the minimum possible value of $\varepsilon^{e}$ is $-i^{*}$. As pointed out earlier, the larger $\varepsilon^{e}$ is, the smaller both $u$ and $\bar{u}$ are. Let us assume even at $\varepsilon_{\min }^{e}=-i^{*}$, both $u$ and $\bar{u}$ are in the range of the magnitude of possible shocks, $[-\mu, \mu]$. This condition will be satisfied if $c$ and $\bar{c}$ are small enough. A higher $\varepsilon^{e}$ will shift both $u$ and $\bar{u}$ towards the smallest possible shock, $-\mu$. If $\varepsilon^{e}$ is high enough, $u$ will reach $-\mu$, which will eliminate the possibility of revaluation since any shock will be larger than $u$. If $\varepsilon^{e}$ is high enough so that $\bar{u}$ reaches $-\mu$, then a crisis becomes self-fulfilling regardless of the magnitude of the shock, $u$. More specifically, $d \bar{u} / d \varepsilon^{e}=d u / d \varepsilon^{e}=-\alpha$ from eqs. (17) and (18) when $u$ and $\bar{u}$ lie in the range of $[-\mu, \mu]$, but $d u / d \varepsilon^{e}=0$ once $u=-\mu$ under higher $\varepsilon^{e}$, and $d \bar{u} / d \varepsilon^{e}=0$ once $\varepsilon^{e}$ is so high that $\bar{u}=-\mu$. Therefore

$$
\begin{aligned}
& \frac{d E \varepsilon}{d \varepsilon^{e}}= \\
& \frac{\alpha^{2} \gamma(1-\phi)(2-\phi)}{\beta\left[\alpha^{2}+\gamma(1-\phi)^{2}\right]+\alpha^{2} \gamma(2-\phi)^{2}} \text { for } u>-\mu \\
& \frac{\alpha^{2} \gamma(1-\phi)(2-\phi)}{\beta\left[\alpha^{2}+\gamma(1-\phi)^{2}\right]+\alpha^{2} \gamma(2-\phi)^{2}}\left(\frac{1}{2}+\frac{\alpha \varepsilon^{e}}{2 u}\right)+\frac{1}{2 u} \frac{\alpha^{3} \gamma(2-\phi) \bar{g}}{\beta\left[\alpha^{2}+\gamma(1-\phi)^{2}\right]+\alpha^{2} \gamma(2-\phi)^{2}} \text { for } u=-\mu \\
& \frac{\alpha^{2} \gamma(1-\phi)(2-\phi)}{\beta\left[\alpha^{2}+\gamma(1-\phi)^{2}\right]+\alpha^{2} \gamma(2-\phi)^{2}} \text { for } \bar{u}=-\mu
\end{aligned} .
$$

Figure 1 shows how there can be three equilibrium expected devaluation rates, $\varepsilon_{1}, \varepsilon_{2}$, and $\varepsilon_{3}$, corresponding to three different probabilities and magnitudes of devaluation. At the first two possible equilibria, note at either $\varepsilon_{l}$ or $\varepsilon_{z}, \bar{u}$ falls within the possible range of the shock $(-\mu<\bar{u}<\mu)$ and thus whether a devaluation/crisis will happen depends on whether the shock $u$ is larger or smaller than $\bar{u}$. Therefore crises are "contingent". Obviously $\bar{u}$ is smaller if $\varepsilon^{e}=\varepsilon_{2}>\varepsilon_{1}$ and a crisis is more likely. Once $\varepsilon^{e}$ has risen high enough that $\bar{u}$ is stuck at $-\mu$, the government's reaction function is simply the same as under a floating regime (eq. (13')) and $\varepsilon_{3}$ is just the expected depreciation level under a floating regime (eq. (13)) which we have 
studied earlier. ${ }^{4}$ As pointed out by Obstfeld (1996), such an equilibrium has to exist if there are to be multiple equilibria at all. Different from equilibrium 1 and 2, equilibrium 3 is purely self-fulfilling - it will happen if people expect it to happen, regardless of the magnitude of

the shock, as any $u$ will be larger than $\bar{u}$ once $\varepsilon^{e}$ reaches $\varepsilon_{3}$.

The sufficient condition for equilibrium 3 to exist is that at the intersection of eq. (13) and the 45-degree line (thus an equilibrium), $\varepsilon^{e}$ is high enough that $\bar{u} \leq-\mu . \varepsilon_{3}$ is essentially the expected depreciation under a floating regime and was solved in eq. (13). Plugging eq. (13) into eq. (17) to solve for $\bar{u}$ under $\varepsilon_{3}$, which we denote as $\bar{u}_{3}$ :

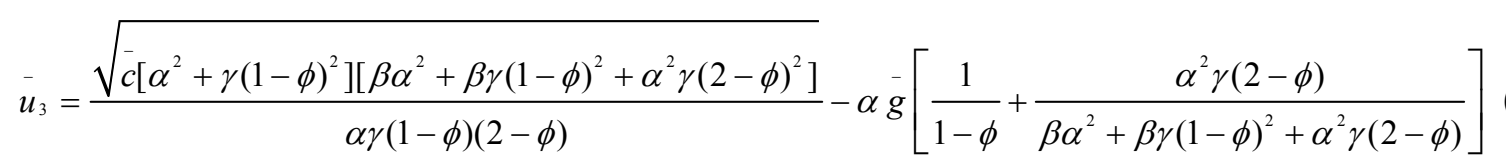

Obviously $\bar{u}_{3}$ has to be negative. The condition for the self-fulfilling crisis equilibrium 3 to exist is $\bar{u}_{3}<-u$ :

$$
\frac{\sqrt{\bar{c}\left[\alpha^{2}+\gamma(1-\phi)^{2}\right]\left[\beta \alpha^{2}+\beta \gamma(1-\phi)^{2}+\alpha^{2} \gamma(2-\phi)^{2}\right]}}{\alpha \gamma(1-\phi)(2-\phi)}-\alpha \bar{g}\left[\frac{1}{1-\phi}+\frac{\alpha^{2} \gamma(2-\phi)}{\beta \alpha^{2}+\beta \gamma(1-\phi)^{2}+\alpha^{2} \gamma(2-\phi)}\right]<-u\left(20{ }^{\prime}\right)
$$

This condition implies that if markets expect the exchange rate to devalue, it will, regardless of the magnitude of the output shock. In other words, it guarantees the existence of a selffulfilling devaluation equilibrium. In the next section, we analyze the conditions that affect the likelihood for eq. (20') to hold.

\section{INSTITUTIONAL QUALITY AND SELF-FULFILLING CURRENCY CRISES}

In eqs. $\left(20^{\prime}\right)$, we derived the condition under which there will exist a self-fulfilling crisis equilibrium. This condition is more likely to hold if the devaluation $\cos t \bar{c}$ is low, the desired public goods provision $\bar{g}$ is high, the weight on public goods provision $\gamma$ is high, and the devaluation aversion $\beta$ is low. These conditions are all intuitive: when the government highly values a high level of public goods provision, it is more likely to use devaluation/inflation to raise the revenue needed especially when the fixed and social costs of devaluation/inflation are low. People foresee this and increase their devaluation expectation, making the existence

\footnotetext{
${ }^{4}$ The slope of $E \varepsilon^{\text {Float }}$ w.r.t. $\varepsilon^{e}$ is positive but can be shown is smaller than one.
} 
of a self-fulfilling crisis more likely. The impact of $\alpha$, the slope of the supply curve, is ambiguous and will in general depend on the values of the parameters in the model.

We next differentiate $\bar{u}_{3}$ w.r.t. the index of institutional weakness $\phi$, a negative slope implies the existence of a self-fulfilling crisis equilibrium is more likely for countries with weaker institutions. The derivative is:

$$
\begin{aligned}
& \frac{d \bar{u}_{3}}{d \phi}=\frac{\alpha^{3} \beta \gamma \bar{g}\left[\alpha^{2}-\gamma(1-\phi)(3-\phi)\right]}{\left[\beta \alpha^{2}+\beta \gamma(1-\phi)^{2}+\alpha^{2} \gamma(2-\phi)\right]^{2}}-\frac{\alpha \bar{g}}{(1-\phi)^{2}} \\
& +\frac{\sqrt{-}}{\alpha \gamma(1-\phi)^{2}(2-\phi)^{2}} \frac{\alpha^{4} \beta(3-2 \phi)+2 \alpha^{2} \beta \gamma(1-\phi)^{3}+\alpha^{4} \gamma(2-\phi)^{3}-\beta \gamma^{2}(1-\phi)^{4}}{\sqrt{\left[\alpha^{2}+\gamma(1-\phi)^{2}\right]\left[\beta \alpha^{2}+\beta \gamma(1-\phi)^{2}+\alpha^{2} \gamma(2-\phi)^{2}\right.}}
\end{aligned}
$$

From the first item, we can see that the sign of $d \bar{u}_{3} / d \phi$ will more likely to be negative if the condition $\gamma(1-\phi)(3-\phi)-\alpha^{2}>0$ holds, which is the same condition under which weaker institutions will lead to a larger expected devaluation under realignment. But the overall sign of $d \bar{u}_{3} / d \phi$ will generally depend on the parameter values in the model and the value of $\phi$ and we would have to utilize simulation exercises. In choosing parameter values, we follow the practice of Obstfeld (1994) and set the slope of the supply curve $\alpha=1$, the public good

provision target $\bar{g}=0.35$, the fixed cost of realignment $\bar{c}=0.0008$. We also set the inflation aversion coefficient $\beta$ to be one as in Obstfeld (1997), and the weight on public good provision $\gamma=\beta=1$. Figure 2 a plots $\bar{u}_{3}$ against the index of institutional weakness under these parameters. Figure 2 a shows that $-\bar{u}_{3}$ is always smaller under weaker institutions, making the existence of a purely self-fulfilling equilibrium more likely. In fact, under these parameter values there would always exist a self-fulfilling crisis equilibrium for reasonable range of output shocks.

What Obstfeld had in mind when constructing the second generation model of currency crises was the European Monetary System crisis during 1992-1993. The implicit sample in our study, however, are developing countries with weak institutions. As a robustness check, figure $2 \mathrm{~b}$ plots $\bar{u}_{3}$ on institutional weakness using a smaller supply curve $\alpha=0.25$ with other parameter values remaining the same. The value of $\bar{u}_{3}$ is again always smaller with weaker institutions, making the existence of a self-fulfilling crisis equilibrium more likely. In addition, under these parameter values, there would always exist a self-fulfilling crisis equilibrium for reasonable range of output shocks when institutions are weak enough (larger value of $\phi$ ).

Various combinations of other parameter values show that $\bar{u}_{3}$ is generally smaller for countries with weaker institutions, making the existence of a self-fulfilling crisis more likely. On the other hand, under certain parameter values this relationship may reverse with very 
Figure 2a. Simulation I



Figure 2b. Simulation II

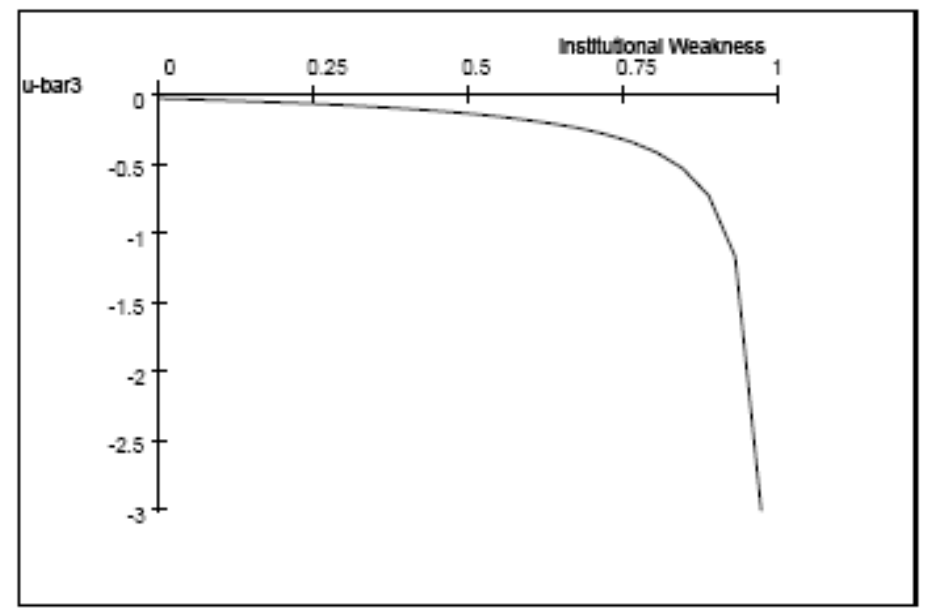

Figure 2c. Simulation III




severe institutional problems. Figure $2 \mathrm{c}$ plots $\bar{u}_{3}$ on institutional weakness using $\alpha=0.25$, a higher realignment cost of $\bar{c}=0.003$, and a smaller weight on public goods provision $\gamma=0.15$, with all other parameter values remaining the same as in figure $2 b$. These changes will make the existence of a self-fulfilling crisis less likely as pointed out earlier. Here the value of $\mathrm{u}_{3}$ is smaller when institutions are moderately weak but becomes larger with very weak institutions, making the existence of a self-fulfilling crisis equilibrium less likely. This is because as eq. (15) shows, with very weak institutions, an even higher level of institutional weakness could lead to smaller expected devaluation, thus making a self-fulfilling crisis less likely.

If the self-fulfilling crisis equilibrium 3 materializes, eq. (15) shows that the mean devaluation rate will be larger for countries with weaker institutions as long as the condition $\gamma(1-\phi)(3-\phi)-\alpha^{2}>0$ holds, which is more likely to be the case for countries with lower institutional quality.

\section{CONCLUDing REMARKS}

In this paper we studied how institutional quality affects the probability of currency crises using an extended Obstfeld (1996) type model, with weak institutions causing a leakage of tax revenue as in Huang and Wei (2006). As a result, the authorities may have to rely more on seigniorage, thus increasing their incentive to deviate from the exchange rate peg. We find weak institutions generally increases the likelihood of the existence of a self-fulfilling crisis equilibrium. In addition, when a self-fulfilling crisis materializes, countries with weak institutions are likely to have larger devaluations. However, when institutional weakness is more severe beyond a threshold, the devaluation needed to compensate for the tax revenue loss could be so large that the gain in welfare from meeting the public goods provision is more than offset by the increase in social loss due to higher inflation/devaluation. As a result, the optimal devaluation could be smaller, and the existence of a self-fulfilling crisis equilibrium becomes less likely. 


\section{References}

Alesina, Alberto and Tabellini, Guido, 1987, "Rules and Discretion with Noncoordinated Monetary and Fiscal Policies." Economic Inquiry, August, 25(4), pp.619-30.

Barro, Robert J., and David B. Gordon, 1983, "A positive theory of monetary policy in a natural rate model." Journal of Political Economy 91, 589-610.

Huang, Haizhou, and Shang-Jin Wei, 2006, "Monetary Policy for Developing Countries: The Role of Institutional Quality." Journal of International Economics 79: 239-252.

Johnson, Simon, Peter Boone, Alasdair Breach, and Eric Friedman (2000), "Corporate Governance in the Asian Financial Crisis." Journal of International Economics (58)1-2: 141-186.

Krugman, Paul, 1979, "A Model of Balance of Payment Crises." Journal of Money, Credit and Banking (11): 311-325.

Mauro, Paolo, 1995, "Corruption and Growth." Quarterly Journal of Economics, 110: 681-712.

Obstfeld, Maurice, 1994, "The Logic of Currency Crises." Cahiers Ecolnomiques et Monetarires (Banque de France) 43: 189-213. , 1996, "Models of Currency Crises with Self-fulfilling Features." European Economic Review, Vol. 40, 1037-1047.

, 1997, "Destabilizing Effects of Exchange-rate Escape Clauses." Journal of International Economics (43): 61-77.

Radelet, Steven, and Jeffrey D. Sachs, "The East Asian Financial Crisis: Diagnosis, Remedies, Prospects." Brookings Papers on Economic Activity, 1998 (1), pp.1-90.

Wei, Shang-Jin, 2000a, "How Taxing is Corruption on International Investors?" Review of Economics and Statistics, February, 82(1): 1-11. , 2000b, "Local Corruption and Global Capital Flows," Brookings Papers on Economic Activity, 2000(2). 